\title{
COMPACTAÇÃO DO SOLO E PRODUÇÃO DE CULTIVARES DE MILHO EM LATOSSOLO VERMELHO. I - CARACTERÍSTICAS DE PLANTA, SOLO E ÍNDICE $S^{(1)}$
}

\author{
Onã da Silva Freddi ${ }^{(2)}$, José Frederico Centurion ${ }^{(3)}$, Aildson Pereira Duarte $^{(4)} \&$ \\ Cristian Luarte Leonel ${ }^{(5)}$
}

\begin{abstract}
RESUMO
Este trabalho teve como objetivo avaliar, em condições de campo, a resposta de duas cultivares de milho com características genéticas distintas em Latossolo Vermelho em seis níveis de compactação. $O$ experimento foi conduzido em faixas, no delineamento de blocos completos casualizados, com quatro repetições. Utilizaram-se os híbridos de milho DKB 390 e DAS 2B710. Após a semeadura do milho, coletaram-se amostras indeformadas de solo nas profundidades de $\mathbf{0}-10$, 10-20 e 20-30 cm, para determinação de propriedades físicas do solo e índice $S$. No estádio de maturidade físiológica dos grãos do milho, foram determinados: a altura das plantas, a altura de inserção da primeira espiga, o diâmetro do segundo colmo acima do solo e a massa de matéria seca das plantas. As espigas foram colhidas e debulhadas para determinação da produtividade de grãos, corrigida para a umidade-padrão de $13 \%$, calculando-se também o número de espigas por planta e o índice de colheita. $O$ índice $S$ apresentou correlação positiva com a produtividade, porém, abaixo do limite de $\mathrm{S} \leq \mathbf{0 , 0 3 5}$, estabelecido para uma condição de solo desestruturado, ocorreram perdas acentuadas na produtividade de milho. Os híbridos simples de milho DKB 390 e DAS 2 B710 não apresentaram diferenças quando submetidos aos diferentes níveis de compactação. A produtividade dos híbridos de milho foi significativamente menor quando a resistência do solo à penetração atingiu 2,15 MPa.
\end{abstract}

Termos de indexação: resistência do solo à penetração, conteúdo de água, Zea mays.

\footnotetext{
(1) Parte da Tese de Pós-Doutorado do primeiro autor. Recebido para publicação em julho de 2008 e aprovado em maio de 2009.

(2) Pós-Doutorando da Faculdade de Ciências Agrárias e Veterinárias, Universidade Estadual Paulista - UNESP. Departamento de Solos e Adubos. Via de Acesso Prof. Paulo Donato Castellane s/n, CEP 14884-900 Jaboticabal (SP). Bolsista FAPESP. Email: onafreddi@gmail.com

${ }^{(3)}$ Professor Adjunto, Departamento de Solos e Adubos. Faculdade de Ciências Agrárias e Veterinárias, UNESP. Bolsista CNPq. E-mail: jfcentur@fcav.unesp.br

(4) Pesquisador da APTA Regional Médio Paranapanema. CEP 19802-970 Assis (SP). E-mail: aildson@aptaregional.sp.gov.br

${ }^{(5)}$ Doutorando da Faculdade de Ciências Agrárias e Veterinárias, UNESP. E-mail: crleonel@yahoo.com.br
} 


\title{
SUMMARY: SOIL COMPACTION AND PRODUCTION OF CORN CULTIVARS IN AN OXISOL. I - PLANT CHARACTERISTICS, SOIL AND S INDEX
}

\begin{abstract}
The purpose of this study was to evaluate, under field conditions, in Colina-SP, Brazil, the response of two genetically different corn cultivars to six compaction levels of an Oxisol. The experiment was arranged in a randomized complete block design, with strip plots and four replications. The corn hybrids DKB 390 and DAS $2 B 710$ were used. After corn seeding, nondeformed soil samples were collected from the layers 0-0.10, 0.10-0.20 and 0.20-0.30 m to determine soil physical properties and the $S$ index. At the seed maturity stage, plant height, height of ear insertion, stem diameter and plant mass were measured. The ears were harvested and threshed to determine grain yield (moisture corrected to standard $13 \%$ ) and the number of ears per plant and harvest index were also calculated. The $S$ index was positively correlated with grain yield. However, below the $S$ threshold of $£ 0.035$, established for soil without structure, the corn yield losses were great. The simple hybrids DKB 390 and DAS $2 B 710$ did not differ under different soil compaction levels. The grain yields of both were significantly lower when soil resistance to penetration reached $2.15 \mathrm{MPa}$.
\end{abstract}

Index terms: soil resistance to penetration, water content, Zea mays.

\section{INTRODUÇÃO}

Em geral, a resposta das plantas à compactação varia de acordo com os solos, as condições de umidade (Silva et al., 2006; Beutler et al., 2007), as culturas (Silva \& Rosolem, 2001) e as cultivares (Beutler et al., 2006; Silva et al., 2006). Na maioria dos estudos sobre compactação do solo e desenvolvimento das culturas, pequena atenção é dada às diferenças genéticas dos materiais em relação ao seu desenvolvimento e estabelecimento em solos compactados (Soyelu et al., 2001).

Em experimento realizado em casa de vegetação com compactação artificial do subsolo, Kasperbauer \& Busscher (1991) observaram para o genótipo de algodão PD-1 que 75 \% das raízes penetraram através de uma camada compactada de densidade do solo igual a $1,4 \mathrm{~kg} \mathrm{dm}^{-3}$, o que não foi observado para o genótipo PD-695. Yu et al. (1995), avaliando 11 cultivares de arroz, constataram variação de 6 a $25 \%$ na penetração de raízes em camadas compactadas. O mesmo foi observado por Bushamuka \& Zobel (1998) em cultivares de soja e milho cultivadas em vasos.

Estudando o efeito da compactação do solo em cultivares de soja, Borges et al. (1988) verificaram que a cultivar Tropical foi mais sensível, comparada à Bossier, Cristalina, Doco e IAC-b. Queiroz-Voltan et al. (2000) verificaram que, com o aumento da compactação, ocorreu decréscimo linear da altura e do número de vagens da cultivar de soja IAC-8 e uma resposta quadrática da cultivar IAC-14, com decréscimo a partir de $1,35 \mathrm{~kg} \mathrm{~L}^{-1}$ terceiro nível de compactação. Beutler et al. (2006), avaliando o desenvolvimento de cultivares de soja em um Latossolo Vermelho submetido a diferentes níveis de compactação, observaram que o valor de resistência do solo à penetração, a partir do qual ocorreu redução da produtividade, variou entre as cultivares.

Pelo fato de a compactação ser um sério problema para os solos agrícolas, seu estudo é intenso, bem como também a busca por medidas que permitam a comparação entre os diferentes solos (Almeida et al., 2008). O reconhecimento da ocorrência dessas interações (tipo de solo x compactação) e de que as produções das culturas estão sujeitas às suas interferências demonstra a necessidade de quantificálas na avaliação da influência das práticas de manejo sobre as condições físicas do solo (Tormena et al., 1998; Silva et al., 2008). Logo, o efeito das práticas de cultivo sobre a qualidade do solo deve ser monitorado, principalmente aquelas relacionadas com a estrutura, a distribuição do tamanho dos poros e as propriedades hídricas do solo, como os fluxos e a disponibilidade de água às plantas. Para isso, indicadores de qualidade do solo têm sido empregados, como, por exemplo, o índice $S$.

O índice $S$, apresentado nos trabalhos de Dexter (2004a,b,c), calculado a partir da curva de retenção de água, apresenta importante contribuição nos estudos da qualidade física do solo para crescimento e produtividade das culturas, sobretudo pelo grande potencial para ser usado em avaliações da interação entre o manejo e a física do solo e por ser facilmente medido, com equipamentos e equações utilizados rotineiramente nos laboratórios de física do solo. Ele é definido como a declividade da curva de retenção de água no solo no seu ponto de inflexão. Segundo Dexter (2004a), a maior declividade S no ponto de inflexão é resultante, principalmente, da maior porosidade estrutural, que compreende as microfendas, fendas, 
bioporos e macroestruturas produzidos pelo preparo do solo; portanto, S reflete diretamente muitos dos principais atributos físicos do solo.

A análise das curvas de retenção de água na literatura sugere que a degradação física do solo sempre conduz a uma mudança no formato das curvas. Uma pequena inclinação indica um solo desestruturado e, portanto, uma elevada inclinação, um solo estruturado e que possui muitos poros (Dexter, 2004a); esse autor, estabelece o valor de S igual ou inferior a 0,035 para uma condição de solo degradado, e igual ou inferior a 0,020 como limite para um solo extremamente degradado, que pode ser devido à redução da porosidade estrutural e ao aumento da densidade do solo. Tormena et al. (2008), avaliando o índice $S$ em um Latossolo Vermelho, na linha e na entrelinha da cultura de milho sob sistemas de plantio direto e preparo convencional, verificaram maiores valores desse índice sob plantio direto e na linha de plantio. Esses pesquisadores concluíram que o valor de S diminuiu com o aumento da densidade do solo, indicando a redução da sua qualidade física, associada à sua compactação.

Dessa forma, a compreensão e a quantificação do impacto do uso e manejo do solo na sua qualidade física são fundamentais no desenvolvimento de sistemas agrícolas sustentáveis. Assim, há necessidade de estudos que relacionem esses novos indicadores físicos com a produção das culturas, na tentativa de definir valores aplicáveis no campo, já que são escassas as informações nesse sentido para os solos do Brasil.

O objetivo deste trabalho foi avaliar, em condições de campo, a resposta de duas cultivares de milho com características genéticas distintas, em um Latossolo Vermelho submetido a diferentes níveis de compactação, quanto a características agronômicas da cultura, bem como caracterizar a compactação do solo a partir do índice $S$.

\section{MATERIAL E MÉTODOS}

O experimento foi realizado em Colina (SP), situada nas coordenadas geográficas de $20^{\circ} 43^{\prime} 29^{\prime \prime}$ de latitude sul e $48^{\circ} 34^{\prime} 26$ " de longitude oeste, com altitude média de $599 \mathrm{~m}$. A área utilizada para o experimento vinha sendo usada para pasto e apenas nas safras de verão 2005/2006 e 2006/2007 foi cultivada com milho, no sistema de preparo convencional do solo.

O solo utilizado é um Latossolo Vermelho distrófico típico textura média hipoférrico muito profundo revelo suave ondulado (Typic Haplustox), irrigado por sistema de pivô central. Foi determinada, para a profundidade de 0-20 cm, a composição granulométrica do solo em amostras deformadas, utilizando-se o método da pipeta (Gee \& Bauder, 1986). O Latossolo Vermelho apresentou na profundidade de $0-20 \mathrm{~cm}$ valores médios de $210 \mathrm{~g} \mathrm{~kg}^{-1}$ de argila, $70 \mathrm{~g} \mathrm{~kg}^{-1}$ de silte,
$330 \mathrm{~g} \mathrm{~kg}^{-1}$ de areia fina e $390 \mathrm{~g} \mathrm{~kg}^{-1} \mathrm{de}$ areia grossa. Antes da instalação do experimento, foi feita a escarificação do solo até $30 \mathrm{~cm}$ de profundidade, seguida de uma gradagem leve.

O experimento foi conduzido em faixas no delineamento de blocos completos casualizados, com quatro repetições. Os tratamentos foram constituídos pela combinação de seis níveis de compactação do solo e duas cultivares de milho. Toda parcela experimental apresentou cinco linhas de milho com $6 \mathrm{~m}$ de comprimento, considerando-se área útil as três linhas centrais e desprezando-se 1,5 m de cada extremidade.

Os níveis de compactação foram assim estabelecidos: $\mathrm{T} 1$ = solo preparado (escarificação e gradagem), sem tráfego de tratores; $\mathrm{T} 2=$ uma passada do trator de $4 \mathrm{t}$; T3 = uma passada do trator de $6 \mathrm{t}$; T4 = duas passadas do trator de $6 \mathrm{t}$; T5 = quatro passadas do trator de 6 t; e T6 = oito passadas do trator de 6 t, no sentido do declive da área, uma ao lado da outra, ou seja, repetindo-se essa operação até completar toda a superfície do solo, que apresentava conteúdo de água na capacidade de campo $\left(0,17 \mathrm{~kg} \mathrm{~kg}^{-1}\right)$. As cultivares foram semeadas em sentido perpendicular aos tratamentos de compactação.

Os tratores utilizados para estabelecer os diferentes níveis de compactação são empregados na fazenda para preparo do solo, plantio, pulverização e outras atividades. No tratamento T2 utilizou-se o trator de pneus Massey Fergusson 275 de $51,5 \mathrm{~kW}$ (70 cv), tração $4 \times 2$ e massa de $4 \mathrm{t}$, com distribuição de $30 \%$ da massa total nas rodas dianteiras e $70 \%$ nas rodas traseiras. A área de contato do pneu com o solo foi estimada multiplicando-se a largura pelo maior comprimento do pneu em contato com o solo. As pressões na área de contato roda-solo resultaram em 0,46 e $0,20 \mathrm{MPa}$ para os rodados dianteiros e traseiros, respectivamente. $\mathrm{O}$ trator utilizado nos tratamentos T2 a T6 foi o Valtra BM 110 de $80,9 \mathrm{~kW}(110 \mathrm{cv})$, tração 4 x 2 TDA (tração dianteira auxiliar) e massa de 6 t, com distribuição de $40 \%$ da massa total nas rodas dianteiras e $60 \%$ nas rodas traseiras. As pressões de contato roda-solo resultaram em 0,21 e $0,25 \mathrm{MPa}$ para os rodados dianteiros e traseiros, respectivamente.

O controle da irrigação foi realizado por meio de seis baterias de tensiômetros instaladas nos tratamentos T1 e T6; cada bateria foi composta por três tensiômetros, nas profundidades de 10,20 , e $30 \mathrm{~cm}$. Quando a média entre as leituras dos tensiômetros de decisão $(20 \mathrm{~cm})$ foi próxima ao valor da tensão de água no solo de $400 \mathrm{hPa}$ utilizou-se a irrigação para elevar a tensão de água do solo para capacidade de campo (100 hPa).

A análise química de rotina para fins de fertilidade seguiu o método proposto por Raij et al. (1987). O solo foi adubado para obtenção da produtividade esperada de milho de 10-12 t ha-1, segundo Raij et al. (1997). No dia 10 de maio foram semeados, com uma semeadora de plantio direto, os híbridos simples de 
milho (Zea mays L.) DKB 390, da empresa DEKALB, e DAS 2B710, da empresa Dow AgroScience, no espaçamento de $0,85 \mathrm{~m}$ entrelinhas. Foram distribuídas sementes em excesso e, cerca de 15 dias após a emergência, realizou-se o desbaste para obter a população de 58.800 plantas $_{\text {ha }}{ }^{-1}$. As adubações de cobertura foram realizadas aos 19 e 35 dias após a emergência das plântulas, utilizando-se em cada uma delas $155 \mathrm{~kg} \mathrm{ha}^{-1}$ de ureia, aplicados sem incorporação, quando as plantas estavam com aproximadamente três e seis folhas, respectivamente.

Após a semeadura do milho, foram coletados, em duas trincheiras por faixa de compactação, conjuntos de sete amostras indeformadas de solo, com cilindros de $54,28 \mathrm{~cm}^{3}$ (3 $\mathrm{cm}$ de altura e $4,8 \mathrm{~cm}$ de diâmetro), no centro das profundidades de $0-10,10-20$ e 20 $30 \mathrm{~cm}$, totalizando 42 amostras por nível de compactação e 252 amostras no experimento para determinação dos atributos e indicadores físicos do solo. Para determinar a curva de retenção de água do solo, foi adotado o procedimento descrito em Silva et al. (1994); as amostras foram divididas em sete grupos de 36 cilindros, sendo duas amostras por faixa de compactação e camada do solo. Após devidamente preparadas, as amostras foram saturadas, por ascensão capilar em uma bandeja, e então cada grupo de cilindros foi submetido a uma única tensão, sendo as tensões utilizadas de 10,60,100,330,600, $1.000 \mathrm{e}$ $3.000 \mathrm{hPa}$, em câmaras de Richards (Klute, 1986). Ao atingirem o equilíbrio, as amostras indeformadas foram pesadas, determinando-se a resistência do solo à penetração $(\mathrm{RP})$ com duas repetições por amostra, na profundidade de 1 a $2 \mathrm{~cm}$, perfazendo 100 leituras por repetição, que foram utilizadas para obtenção da RP média de cada cilindro. A RP foi determinada por meio de um penetrômetro eletrônico estático, com velocidade constante de penetração de $1 \mathrm{~cm} \mathrm{~min}^{-1}$, cone com ângulo de $30^{\circ}$ e área da base de $4,909 \mathrm{x} \mathrm{cm}^{2}$, equipado com atuador linear e célula de carga de 20 $\mathrm{kg}$ acoplada a um microcomputador para aquisição dos dados, conforme descrito por Tormena et al. (1998). Na sequência, as amostras foram secas em estufa a $105{ }^{\circ} \mathrm{C}$ durante $24 \mathrm{~h}$, para determinação do conteúdo de água em cada tensão (Gardner, 1986) e densidade do solo (Blake \& Hartge, 1986). A microporosidade foi determinada por secagem em câmaras de pressão de Richards com placa porosa (Klute, 1986) na tensão de $100 \mathrm{hPa}$; a porosidade total, segundo Danielson \& Sutherland (1986); e a macroporosidade foi obtida por diferença entre a porosidade total e a microporosidade. Como foram determinadas apenas duas amostras na tensão de $100 \mathrm{hPa}$ por faixa de compactação e profundidade, foram abertas mais seis trincheiras por faixa de compactação, coletando-se uma amostra indeformada em cada profundidade, para determinação da macro e microporosidade na tensão de $100 \mathrm{hPa}$, além da porosidade total e densidade do solo, formando assim quatro repetições por cultivar. Logo, coletaramse 60 cilindros por faixa de compactação e 360 no experimento.
As curvas de retenção de água também foram ajustadas pelo modelo proposto por van Genuchten (1980), a partir do qual foi determinada a declividade da reta tangente em seu ponto de inflexão, obtendo-se o índice $S$ :

$$
\mathrm{S}=n\left(\theta_{\text {sat }}-\theta_{\text {res }}\right)\left[1+\frac{1}{m}\right]^{-(1+m)}
$$

em que $n$ e m são os parâmetros que governam o formato da curva; e $\theta_{\text {sat }}$ e $\theta_{\text {sres }}$ são o conteúdo de água na saturação e residual, respectivamente.

Após o estádio de maturidade fisiológica dos grãos, em 10 plantas por parcela, foram determinados a altura das plantas, a altura de inserção da primeira espiga, o diâmetro do segundo colmo acima do solo e a massa de matéria seca das plantas. A produção de matéria seca foi avaliada em 2,0 m de uma linha útil (foi descartado 0,5 m em cada extremidade da linha de 3,0 m). Após a pesagem, foram amostradas cinco plantas para moagem e determinação do teor de matéria seca em estufa a $60^{\circ} \mathrm{C}$. Esse valor foi multiplicado pela massa de matéria verde da parcela, para obtenção da produção de matéria seca na parcela e por unidade de área, em t ha-1.

Quando a umidade dos grãos foi inferior a $25 \%$, foram colhidas as espigas de duas linhas úteis de 2,0 m, para debulha e determinação da massa de grãos. A produtividade de grãos de milho foi obtida extrapolando-se a produção de grãos da área útil da parcela para um hectare, considerando-se a umidadepadrão de $13 \%$.

Por meio do número final de plantas e de espigas na parcela útil, determinou-se o número de espigas por planta. Calculou-se também o índice de colheita, dividindo a massa de grãos pela massa de matéria seca total da planta.

Os dados foram submetidos aos testes de Shapiro Wilk e Levene, ambos a $5 \%$, para verificação da normalidade dos resíduos e homocedasticidade das variâncias, respectivamente. Todas as variáveis do trabalho apresentaram distribuição normal e homocedasticidade, não havendo necessidade de transformação dos dados.

A análise de variância, para as variáveis relativas à planta, seguiu o esquema de experimento em faixas no delineamento de blocos completos casualizados e, para os atributos físicos do solo, o esquema em faixas no delineamento de blocos completos casualizados com parcelas subdivididas, cujas subdivisões corresponderam às profundidades do solo. As médias das cultivares foram comparadas pelo teste de Tukey a $5 \%$. Para o fator compactação do solo, realizou-se análise por regressão polinomial, e, sendo o teste $\mathrm{F}$ da variância da regressão significativo a $5 \%$, selecionaram-se modelos, adotando-se como critérios o maior $\mathrm{R}^{2}$ e a significância de $5 \%$ dos coeficientes da equação. 


\section{RESULTADOS E DISCUSSÃO}

No quadro 1 é apresentado o resumo da análise de variância das propriedades físicas do solo. Verifica-se que houve interação significativa entre os fatores níveis de compactação e profundidades, para todas as variáveis. Assim, não puderam ser analisados separadamente. Isso indica que as modificações causadas pelo tráfego dos tratores na estrutura do solo (propriedades físicas) foram diferentes conforme cada tratamento e profundidade analisada. Observa-se também que a condição física do solo para o plantio e desenvolvimento das cultivares foi homogênea, já que não houve diferença para o fator cultivar, assim como entre quaisquer interações em que tal fator estivesse presente. Logo, as duas cultivares tiveram as mesmas condições de expressar seu potencial produtivo, e qualquer diferença entre os dois materiais não se deveu à condição física do solo e sim do material.

Observa-se que, em todas as propriedades físicas (Quadro 1), os maiores coeficientes de variação foram obtidos no fator compactação, demonstrando que o tráfego dos tratores causou maior dispersão dos dados entre os tratamentos. Para o fator compactação, a macroporosidade e a resistência do solo à penetração foram as variáveis mais sensíveis às modificações causadas pelo tráfego dos tratores, enquanto a densidade do solo foi pouco modificada, apresentando o menor coeficiente de variação. Os fatores cultivar e profundidade mostraram coeficientes de variação próximos e classificados como baixos $(<10 \%)$ e médios (10 a $20 \%$ ), segundo Gomes (1984), com exceção apenas da resistência do solo à penetração, cujo coeficiente de variação foi classificado como alto (> $20 \%$ ), porém bem inferior ao coeficiente de variação apresentado para o fator compactação, classificado como alto (> $30 \%$ ), o que demonstra baixa dispersão dos dados entre as cultivares e entre as profundidades do solo.

Observa-se no tratamento T1 (Quadro 2) que o preparo do solo com escarificador proporcionou condições físicas homogêneas até a profundidade de $30 \mathrm{~cm}$; o volume de macroporos foi alterado em profundidade somente quando o solo foi trafegado duas ou mais vezes pelo trator de $6 \mathrm{t}$ (T4, T5 e T6), reduzindo a macroporosidade na profundidade de $0-10 \mathrm{~cm}$ em relação às de 10-20 e 20-30 cm para os tratamentos T4 e T5. Somente no tratamento T6, onde o solo foi trafegado oito vezes pelo trator de 6 t, houve redução da macroporosidade até a profundidade de $20 \mathrm{~cm}$. Onde ocorreram diferenças significativas entre as médias, a macroporosidade ficou abaixo do limite de $0,10 \mathrm{~m}^{3} \mathrm{~m}^{-3}$, considerado crítico para o desenvolvimento radicular (Thomasson, 1978; Secco et al., 2004). Observa-se que, entre os tratamentos, o tráfego de tratores apenas modificou a macroporosidade nas duas primeiras profundidades. Quanto à profundidade de $0-10 \mathrm{~cm}$, não houve diferença na macroporosidade dos tratamentos T1, T2 e T3, cujos valores foram superiores aos dos demais tratamentos.

Verifica-se que a microporosidade aumentou com o número de passadas dos tratores, nas profundidades de $0-10$ e 10-20 cm (Quadro 2). Nota-se que o tratamento T1 foi significativamente superior ao tratamento T6. Na profundidade de $20-30 \mathrm{~cm}$ não houve diferença entre os tratamentos. Em profundidade, observa-se que nos tratamentos $\mathrm{T} 1 \mathrm{e}$ T3 não houve modificação da microporosidade, o mesmo foi verificado para macroporosidade. Nos tratamentos T5 e T6, a microporosidade foi maior para as profundidades de $0-10$ e $10-20 \mathrm{~cm}$ em relação à

Quadro 1. Valores de F calculados pela análise de variância para macroporosidade, microporosidade, porosidade total, densidade do solo (Ds) e resistência do solo à penetração (RP), nos diferentes níveis de compactação, cultivares e profundidades do Latossolo Vermelho

\begin{tabular}{|c|c|c|c|c|c|}
\hline \multirow{2}{*}{ Causa de variação } & \multicolumn{3}{|c|}{ Porosidade } & \multirow{2}{*}{ Ds } & \multirow{2}{*}{$\mathbf{R P}$} \\
\hline & Macro & Micro & Total & & \\
\hline Compactação (C) & $4,594^{* *}$ & $2,581 \mathrm{~ns}$ & $9,616^{* *}$ & $7,220 * *$ & $11,509^{* *}$ \\
\hline Cultivar (Cult) & $14,736 \mathrm{~ns}$ & $0,007 \mathrm{~ns}$ & $2,196 \mathrm{~ns}$ & $3,565 \mathrm{~ns}$ & $3,068 \mathrm{~ns}$ \\
\hline $\mathrm{C} \times \mathrm{Cult}$ & $0,475 \mathrm{~ns}$ & $0,988^{\mathrm{ns}}$ & $0,881 \mathrm{~ns}$ & $1,032 \mathrm{~ns}$ & $1,018 \mathrm{~ns}$ \\
\hline Profundidade & $11,559^{* *}$ & $22,187^{* *}$ & $2,958 \mathrm{~ns}$ & $6,851^{* *}$ & $30,621^{* *}$ \\
\hline $\mathrm{C} \times$ Profundidade & $5,014^{* *}$ & $3,350^{* *}$ & $2,708^{* *}$ & $5,189 * *$ & $6,623^{* *}$ \\
\hline Cult $x$ Profundidade & $0,316 \mathrm{~ns}$ & $1,045 \mathrm{~ns}$ & $0,156 \mathrm{~ns}$ & $0,371 \mathrm{~ns}$ & $0,066 \mathrm{~ns}$ \\
\hline C x Cult x Profundidade & $0,643 \mathrm{~ns}$ & $1,290 \mathrm{~ns}$ & $0,823 \mathrm{~ns}$ & $0,319 \mathrm{~ns}$ & $0,416 \mathrm{~ns}$ \\
\hline CV1 (\%) & 45,16 & 13,24 & 8,32 & 6,19 & 44,34 \\
\hline CV2 (\%) & 10,01 & 5,91 & 4,68 & 2,66 & 23,18 \\
\hline CV3 (\%) & 15,11 & 6,01 & 6,04 & 3,24 & 16,71 \\
\hline Média geral & 0,122 & 0,244 & 0,368 & 1,412 & 1,281 \\
\hline
\end{tabular}

CV1 (\%): coeficiente de variação referente ao fator compactação; CV2 (\%): coeficiente de variação referente ao fator cultivar; CV3 (\%): coeficiente de variação referente ao fator profundidade do solo. 
Quadro 2. Valores médios e erros-padrão de macroporosidade, microporosidade, resistência à penetração e densidade do solo, nos diferentes níveis de compactação e profundidades do Latossolo Vermelho de textura média

\begin{tabular}{|c|c|c|c|c|c|c|}
\hline \multirow{2}{*}{ Profundidade } & \multicolumn{6}{|c|}{ Nível de compactação } \\
\hline & $\mathbf{T}_{1}$ & $\mathbf{T}_{2}$ & $\mathbf{T}_{3}$ & $\mathbf{T}_{4}$ & $\mathbf{T}_{5}$ & $\mathbf{T}_{6}$ \\
\hline $\mathrm{cm}$ & \multicolumn{6}{|c|}{ Macroporosidade $\left(\mathrm{m}^{3} \mathrm{~m}^{-3}\right)^{(1)}$} \\
\hline $0-10$ & $0,16 \pm 0,05$ aA & $0,14 \pm 0,03 \mathrm{aA}$ & $0,12 \pm 0,04 \mathrm{abA}$ & $0,09 \pm 0,02 \mathrm{bB}$ & $0,08 \pm 0,01 \mathrm{bB}$ & $0,07 \pm 0,01 \mathrm{bB}$ \\
\hline $10-20$ & $0,15 \pm 0,03 \mathrm{aA}$ & $0,13 \pm 0,02 \mathrm{abA}$ & $0,11 \pm 0,01 \mathrm{abA}$ & $0,12 \pm 0,04 \mathrm{abA}$ & $0,13 \pm 0,02 \mathrm{abA}$ & $0,08 \pm 0,03 \mathrm{bB}$ \\
\hline $20-30$ & $0,16 \pm 0,04 \mathrm{aA}$ & $0,14 \pm 0,03 \mathrm{aA}$ & $0,11 \pm 0,02 \mathrm{aA}$ & $0,15 \pm 0,04 \mathrm{aA}$ & $0,14 \pm 0,02 \mathrm{aA}$ & $0,11 \pm 0,04 \mathrm{aA}$ \\
\hline \multirow[t]{2}{*}{ Média } & $0,16 \pm 0,01$ & $0,14 \pm 0,01$ & $0,12 \pm 0,01$ & $0,12 \pm 0,01$ & $0,12 \pm 0,01$ & $0,09 \pm 0,01$ \\
\hline & \multicolumn{6}{|c|}{ Microporosidade $\left(\mathrm{m}^{3} \mathrm{~m}^{-3}\right)^{(1)}$} \\
\hline $0-10$ & $0,23 \pm 0,01 \mathrm{bA}$ & $0,24 \pm 0,01 \mathrm{bA}$ & $0,24 \pm 0,02 \mathrm{bA}$ & $0,25 \pm 0,01 \mathrm{abA}$ & $0,26 \pm 0,01 \mathrm{abA}$ & $0,27 \pm 0,03 \mathrm{aA}$ \\
\hline $10-20$ & $0,24 \pm 0,01 \mathrm{bA}$ & $0,26 \pm 0,02 \mathrm{abB}$ & $0,24 \pm 0,01 \quad \mathrm{bA}$ & $0,24 \pm 0,02 \mathrm{bAB}$ & $0,25 \pm 0,02 \mathrm{abA}$ & $0,28 \pm 0,02 \mathrm{aA}$ \\
\hline $20-30$ & $0,23 \pm 0,01 \mathrm{aA}$ & $0,24 \pm 0,01 \mathrm{aA}$ & $0,23 \pm 0,01 \mathrm{aA}$ & $0,23 \pm 0,03 \mathrm{aB}$ & $0,23 \pm 0,00 \mathrm{aB}$ & $0,24 \pm 0,02 \mathrm{aB}$ \\
\hline \multirow[t]{2}{*}{ Média } & $0,24 \pm 0,00$ & $0,25 \pm 0,00$ & $0,24 \pm 0,00$ & $0,24 \pm 0,00$ & $0,25 \pm 0,00$ & $0,26 \pm 0,01$ \\
\hline & \multicolumn{6}{|c|}{ Porosidade total $\left(\mathrm{m}^{3} \mathrm{~m}^{-3}\right)$} \\
\hline $0-10$ & $0,40 \pm 0,03 \mathrm{aA}$ & $0,39 \pm 0,02 \mathrm{aA}$ & $0,37 \pm 0,04 \mathrm{abA}$ & $0,34 \pm 0,02 \mathrm{bB}$ & $0,34 \pm 0,01 \mathrm{bB}$ & $0,34 \pm 0,03 \mathrm{bA}$ \\
\hline $10-20$ & $0,39 \pm 0,02 \mathrm{abA}$ & $0,40 \pm 0,04 \mathrm{aA}$ & $0,35 \pm 0,01 \mathrm{cA}$ & $0,36 \pm 0,02 \mathrm{bcAB}$ & $0,38 \pm 0,03 \mathrm{abcA}$ & $0,35 \pm 0,03 \mathrm{cA}$ \\
\hline $20-30$ & $0,39 \pm 0,03 \mathrm{aA}$ & $0,38 \pm 0,04 \mathrm{abA}$ & $0,34 \pm 0,02 \mathrm{bA}$ & $0,37 \pm 0,02 \mathrm{abA}$ & $0,37 \pm 0,02 \mathrm{abA}$ & $0,35 \pm 0,03 \mathrm{bA}$ \\
\hline \multirow[t]{2}{*}{ Média } & $0,39 \pm 0,01$ & $0,39 \pm 0,01$ & $0,35 \pm 0,01$ & $0,36 \pm 0,00$ & $0,36 \pm 0,01$ & $0,35 \pm 0,01$ \\
\hline & \multicolumn{6}{|c|}{ Densidade do solo $\left(\mathrm{kg} \mathrm{dm}^{-3}\right)$} \\
\hline $0-10$ & $1,34 \pm 0,08 \mathrm{cA}$ & $1,34 \pm 0,07 \mathrm{cA}$ & $1,40 \pm 0,10 \mathrm{bcA}$ & $1,53 \pm 0,04 \mathrm{aA}$ & $1,52 \pm 0,04 \mathrm{aA}$ & $1,46 \pm 0,06 \mathrm{abA}$ \\
\hline $10-20$ & $1,37 \pm 0,05 \mathrm{bA}$ & $1,35 \pm 0,04 \mathrm{bA}$ & $1,42 \pm 0,03 \mathrm{abA}$ & $1,47 \pm 0,03 \mathrm{aB}$ & $1,40 \pm 0,05 \mathrm{abB}$ & $1,47 \pm 0,06 \mathrm{aA}$ \\
\hline $20-30$ & $1,36 \pm 0,05 \mathrm{aA}$ & $1,37 \pm 0,04 \mathrm{aA}$ & $1,42 \pm 0,06 \mathrm{aA}$ & $1,37 \pm 0,08 \mathrm{aC}$ & $1,41 \pm 0,05 \mathrm{aB}$ & $1,42 \pm 0,08 \mathrm{aA}$ \\
\hline \multirow[t]{2}{*}{ Média } & $1,35 \pm 0,01$ & $1,35 \pm 0,01$ & $1,41 \pm 0,01$ & $1,46 \pm 0,02$ & $1,45 \pm 0,01$ & $1,45 \pm 0,01$ \\
\hline & \multicolumn{6}{|c|}{ Resistência do solo à penetração $(\mathrm{MPa})^{(1)}$} \\
\hline $0-10$ & $0,89 \pm 0,33 \mathrm{bA}$ & $1,06 \pm 0,36 \mathrm{bA}$ & $1,14 \pm 0,46 \mathrm{bA}$ & $2,09 \pm 0,27 \mathrm{aA}$ & $2,04 \pm 0,31 \mathrm{aA}$ & $2,09 \pm 0,36 \mathrm{aA}$ \\
\hline $10-20$ & $0,85 \pm 0, \mathrm{~b} \quad \mathrm{~A}$ & $0,99 \pm 0,17 \mathrm{bA}$ & $1,08 \pm 0,18 \mathrm{bA}$ & $1,45 \pm 0,57 \mathrm{bB}$ & $1,05 \pm 0,27 \mathrm{bB}$ & $2,21 \pm 0,42 \mathrm{aA}$ \\
\hline $20-30$ & $0,93 \pm 0, a b A$ & $0,99 \pm 0,38 \mathrm{abA}$ & $0,86 \pm 0,22 \mathrm{bA}$ & $0,90 \pm 0,22 \mathrm{abC}$ & $0,89 \pm 0,28 \mathrm{bB}$ & $1,54 \pm 0,50 \mathrm{aB}$ \\
\hline Média & $0,89 \pm 0,06$ & $1,01 \pm 0,06$ & $1,03 \pm 0,06$ & $1,48 \pm 0,13$ & $1,33 \pm 0,12$ & $1,95 \pm 0,10$ \\
\hline
\end{tabular}

Médias seguidas da mesma letra não diferem estatisticamente pelo teste de Tukey a 5 \%. Letras maiúsculas comparam dentro do mesmo tratamento as médias das profundidades, e letras minúsculas comparam na mesma profundidade as médias entre tratamentos. $\mathrm{T} 1=$ solo preparado (escarificação e gradagem), sem tráfego de tratores; T2 = uma passada do trator de $4 \mathrm{t}$; $\mathrm{T} 3=$ uma passada do trator de $6 \mathrm{t}$; T4 = duas passadas do trator de $6 \mathrm{t}$; T5 = quatro passadas do trator de $6 \mathrm{t}$; T6 = oito passadas do trator de 6 t. *: determinação realizada no conteúdo de água retida na capacidade de campo $(100 \mathrm{hPa})$.

profundidade de 20-30 cm; para o T4, houve diferença apenas entre as profundidades de 0-10 e 20-30 cm.

A porosidade total, assim como a macroporosidade, não apresentou diferença em profundidade nos tratamentos T1, T2 e T3 (Quadro 2). Na profundidade de $0-10 \mathrm{~cm}$, os tratamentos T1 e T2 apresentaram maior porosidade total que os tratamentos T4, T5 e T6, ao contrário da profundidade de 10-20 cm, em que o tratamento T1 não diferiu dos tratamentos T2, T4 e T5. Já entre os tratamentos, a porosidade total foi a única propriedade física que teve alteração na profundidade de $20-30 \mathrm{~cm}$, onde os tratamentos T6 e T3 apresentaram menor porosidade em relação ao tratamento T1. Nos tratamentos T1, T2, T3 e T6 não ocorreram diferenças na porosidade total em profundidade. A menor porosidade total no tratamento T6 e seus valores semelhantes em profundidade podem ser explicados pelo maior número de passadas do trator, conseguindo reduzir a porosidade total até a profundidade de $30 \mathrm{~cm}$. Isso não ocorreu nos tratamentos $\mathrm{T} 4$ e $\mathrm{T} 5$, pois a porosidade total foi menor na superfície.

A densidade do solo também mostrou modificação em profundidade nos tratamentos T4 e T5, tendo sido maior na profundidade de 0-10 $\mathrm{cm}$ (Quadro 2). $\mathrm{Na}$ profundidade de 0-10 cm, os tratamentos T4, T5 e T6 não diferiram quanto à densidade do solo, e sim em relação aos tratamentos $\mathrm{T} 1 \mathrm{e} \mathrm{T} 2$. Esse resultado está 
de acordo com a maior porosidade total e macroporosidade apresentada por estes tratamentos (T1 e T2). Na profundidade de $10-20 \mathrm{~cm}$, os tratamentos T4 e T6 mostraram maior compactação em relação aos tratamentos T1 e T2. Na profundidade de $20-30 \mathrm{~cm}$ não houve diferença na densidade entre os tratamentos.

O tráfego de tratores, nos três primeiros tratamentos (T1, T2 e T3), não alterou a resistência do solo à penetração, quando consideradas as diferentes profundidades. Resultado semelhante foi encontrado para as outras propriedades físicas (Quadro 2). No tratamento T4 ocorreu diferença entre todas as profundidades, e a resistência do solo à penetração decresceu com o aumento da profundidade. Já no tratamento $\mathrm{T} 5$ a resistência do solo à penetração foi maior somente na profundidade de $0-10 \mathrm{~cm}$; no tratamento T6, as profundidades de 0-10 e 10-20 cm apresentaram maior resistência do solo à penetração do que a de $20-30 \mathrm{~cm}$, justificando o comportamento da macro e microporosidade, o que não pôde ser observado na porosidade total e densidade do solo. A resistência do solo à penetração foi superior a $2 \mathrm{MPa}$ nos tratamentos T4, T5 e T6 na profundidade de 0 $10 \mathrm{~cm}$, não existindo diferença entre as médias desses tratamentos, mas com resistência superior à dos tratamentos T1, T2 e T3, que também não apresentaram diferença entre si. Quanto à profundidade de 10-20 $\mathrm{cm}$, apenas oito passadas do trator de $6 \mathrm{t}$ (T6) possibilitaram alteração da resistência do solo à penetração, pois os demais tratamentos (T1, T2, T3, T4 e T5) não diferiram. Contudo, na profundidade de $20-30 \mathrm{~cm}$, o tratamento $\mathrm{T} 6$ diferiu apenas de T3 e T5, apresentando maior resistência do solo à penetração.

Nos tratamentos trafegados pelos tratores, a profundidade que mostrou maior intensidade de compactação foi a de $0-10 \mathrm{~cm}$; nesse caso, as propriedades físicas do solo foram alteradas principalmente pela massa do maquinário e pelo número de passadas do trator, concordando com Freddi (2007).

Considerando a média das três profundidades (Quadro 2), verificou-se diminuição no volume de macroporos de $43,75 \%$, aumento na microporosidade de apenas $7,69 \%$ e diminuição de 10,26 \% na porosidade total e de $6,90 \%$ na densidade do solo, quando comparados os tratamentos T1 e T6. Silva et al. (2006) também verificaram que a compactação acarretou decréscimo da porosidade total de 17 e $23 \%$, refletindo em redução da macroposidade de 53 e $67 \%$, e aumento da microposidade de 35 e $32 \%$, respectivamente, em um Latossolo Vermelho-Amarelo oxídico-gibbsítico e em um Latossolo Amarelo caulinítico, na pressão de $900 \mathrm{kPa}$. Esses autores também constataram que a macroporosidade apresentou correlação negativa com a densidade e microporosidade, ou seja, a compactação proporcionou modificação do sistema poroso. Freddi (2007) verificou que o tráfego de tratores sobre um Latossolo Vermelho de textura média proporcionou, na profundidade de 0-20 cm, redução de $71 \%$ da macroporosidade e aumento de 66,25 e $10 \%$ na resistência do solo à penetração, na densidade do solo e na microporosidade, respectivamente.

Observa-se, para as condições deste estudo, que a propriedade física mais sensível à compactação foi a macroporosidade. Nota-se, entretanto, que a densidade do solo, devido à sua pequena variação, não foi tão sensível ao aumento da massa e do número de passadas dos tratores como a resistência do solo à penetração, na qual se verificou uma variação de $54,36 \%$ entre T1 e T6 (média das três profundidades), demonstrando que a resistência do solo à penetração junto com a macroporosidade foram as propriedades físicas mais sensíveis na quantificação da compactação do solo, corroborando os resultados obtidos por Streck et al. (2004) e Abreu et al. (2004).

Com o solo preparado e não trafegado, o índice $S$ foi superior ao valor de 0,035 , considerado limite para um solo com estrutura degradada (Dexter, 2004a), proporcionando condições físicas favoráveis ao desenvolvimento radicular (Figura 1). Contudo, observa-se que apenas uma passada do trator de $4 \mathrm{Mg}$ (T2), considerado um trator leve e de pequeno porte, foi suficiente para reduzir o valor do índice $S$ próximo ao valor de 0,035 nas profundidades de $0-10$ e 10$20 \mathrm{~cm}$. No tratamento T3, apenas a profundidade de 20-30 cm apresentou $\mathrm{S}$ inferior ao valor de 0,035. Observaram-se valores de índice $S$ inferiores a 0,035 na profundidade de $0-10 \mathrm{~cm}$ apenas quando o solo foi trafegado quatro (T5) e oito (T6) vezes pelo trator de

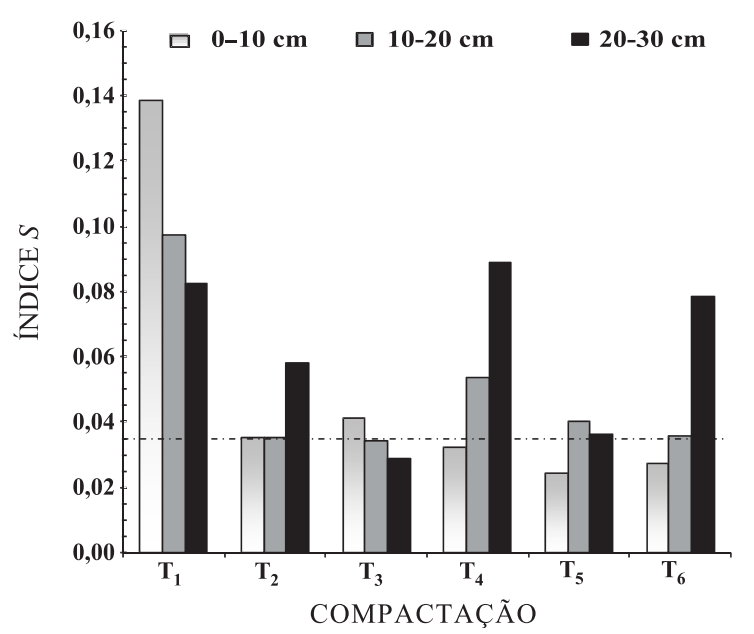

Figura 1. Índice $S$ em diferentes profundidades de um Latossolo Vermelho submetido à compactação: $\mathbf{T} 1$ = solo preparado (escarificação e gradagem), sem tráfego de tratores; $\mathrm{T} 2$ = uma passada do trator de $4 \mathrm{t}$; T3 = uma passada do trator de $6 \mathrm{t}$; T4 = duas passadas do trator de $6 \mathrm{t}$; $\mathrm{T} 5=$ quatro passadas do trator de $6 \mathrm{t}$; T6 $=$ oito passadas do trator de $6 \mathrm{t}$. 
6 t. Segundo Dexter (2004a), a redução de S nas áreas cultivadas pode estar associada a uma diminuição do pico da distribuição de frequência de poros, resultando em um "achatamento" vertical da curva de retenção de água, pela redução dos poros estruturais. Isso demonstra que a perda da qualidade física em razão do tráfego de tratores ocorreu, principalmente, pela redução da macroporosidade, concordando com os resultados observados por Argenton et al. (2005).

Como o tráfego de tratores não modificou a maioria das propriedades físicas na profundidade de $20-30 \mathrm{~cm}$, foi utilizada a média dos dados de $0-20 \mathrm{~cm}$ para cálculo das regressões com as características da parte aérea da planta.

Para os dois híbridos utilizados, o aumento da resistência do solo à penetração de 0,87 a $2,15 \mathrm{MPa}$, na profundidade de $0-20 \mathrm{~cm}$, reduziu linearmente a altura das plantas, o diâmetro do colmo, a massa de matéria seca das plantas e a produtividade de grãos em $8,13,26$ e $23 \%$, respectivamente. Mesmo com a pequena variação na arquitetura das plantas, verificouse elevada redução na produtividade de matéria seca e de grãos de 2,9 e 2,6 t ha ${ }^{-1}$, respectivamente (Figura 2). Freddi (2007) também verificou redução de $12,13,28$ e $38 \%$ para altura das plantas, diâmetro do colmo, massa de matéria seca das plantas e produtividade, respectivamente, em um Latossolo Vermelho de textura média com o aumento da resistência do solo à penetração de 1,65 a $4,81 \mathrm{MPa}$; e de $15,10,24$ e $27 \%$ em um Latossolo Vermelho de textura argilosa com o aumento da resistência do solo à penetração de 0,32 a 1,83 MPa.

Verifica-se que a amplitude da resistência do solo à penetração foi diferente nos três Latossolos, provavelmente devido à diferença na textura e
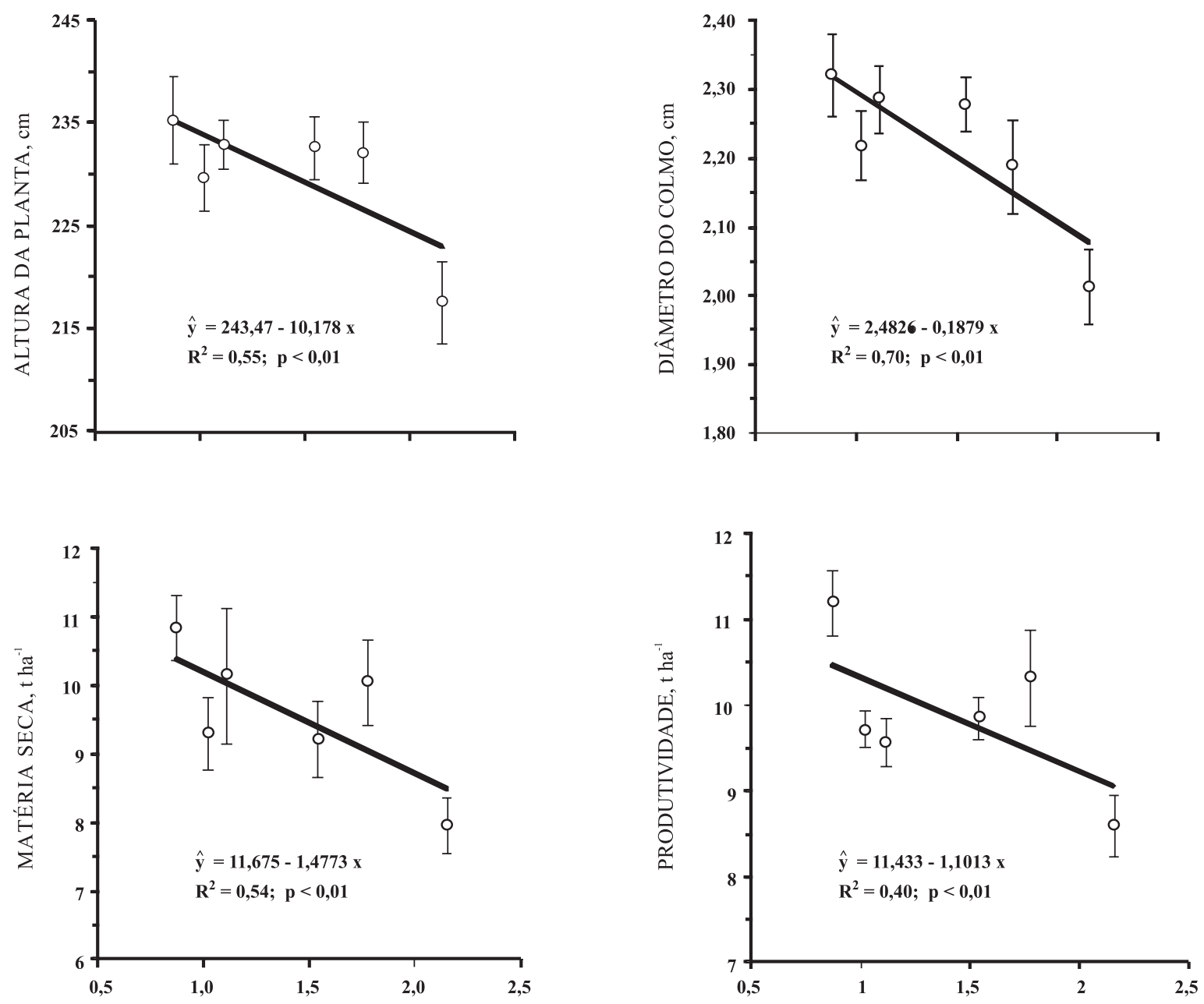

RESISTÊNCIA À PENETRAÇÃO, MPa

Figura 2. Regressão entre a resistência de um Latossolo Vermelho à penetração e a altura das plantas, diâmetro do segundo internódio do colmo, massa de matéria seca e produtividade do milho. As barras referem-se aos intervalos de confiança com os erros-padrão das médias. 
mineralogia desses solos, pois as determinações foram efetuadas com o mesmo tipo de penetrômetro e tensão de água do solo (100 hPa). Todavia, verificou-se o mesmo efeito da compactação sobre o desenvolvimento da cultura do milho, o que impossibilita o estabelecimento de um valor crítico de resistência do solo à penetração. Justificam-se, assim, os resultados contraditórios encontrados na literatura, apresentados por Foloni et al. (2003) e Freddi (2007).

A resistência do solo à penetração crítica foi obtida por meio de regressão entre a produtividade de grãos do milho e os diferentes níveis de compactação do solo. Devido ao comportamento linear dessa relação (produtividade x resistência do solo à penetração), para a determinação do nível crítico de resistência do solo à penetração, adotou-se o critério de Gravetter \& Wallnau (1995). Assim, foi possível diferenciar

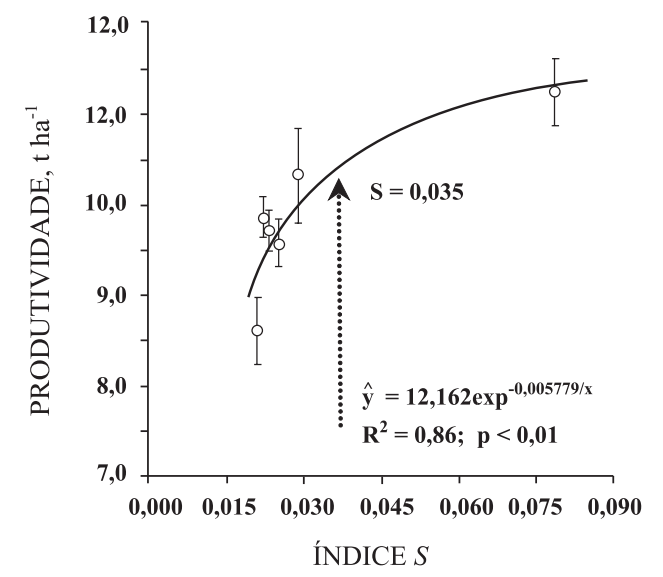

Figura 3. Regressão entre a produtividade de milho e o índice $S$ do Latossolo Vermelho. As barras referem-se aos intervalos de confiança com os erros-padrão das médias. estatisticamente os tratamentos. Essa diferenciação é feita pela não sobreposição dos limites superior e inferior dos erros-padrão das médias dos tratamentos. Dessa forma, verificou-se que apenas a produtividade do tratamento T6 foi significativamente menor (Figura 2). Logo, verificou-se que o valor de 2,15 MPa de resistência do solo à penetração foi crítico para produtividade da cultura do milho.

Verifica-se que a redução do índice $S$, a partir de 0,085, proporcionou diminuição da produtividade de milho, porém numa relação não linear (Figura 3). Somente abaixo de 0,035 de S observa-se uma queda acentuada na produtividade. Com a variação do índice $S$ de 0,035 para 0,020, houve redução na produtividade de 1,201 $\mathrm{tha}^{-1}$, numa variação de apenas 0,015 em S, o que não se verifica quando o índice $S$ varia de 0,085 a 0,035 , reduzindo a produtividade em 1,052 $\mathrm{t} \mathrm{ha}^{-1}$, numa variação em $\mathrm{S}$ de 0,05 .

Partindo-se do valor de 11,362 $\mathrm{t} \mathrm{ha}^{-1}$ de milho atingido com $\mathrm{S}$ igual a 0,085, houve redução de 9,3, 19,8 e $26,9 \%$ na produtividade quando $\mathrm{S}$ foi igual a 0,035, 0,020 e 0,015, respectivamente. Logo, mesmo com o emprego de irrigação, adubação adequada e material genético de alta produtividade, observa-se que os limites de índice $S$ propostos por Dexter (2004a) para uma condição de solo desestruturado $(\mathrm{S} \leq 0,035)$ e extremamente desestruturado $(S \leq 0,020)$ foram atingidos. O índice $S$ foi ótimo indicador da qualidade física do solo e é sensível às modificações impostas à estrutura do solo pelo tráfego de máquinas, refletindo as condições para o desenvolvimento da cultura do milho; pode, assim, ser utilizado para tomadas de decisão em relação ao manejo do solo.

Independentemente do nível de compactação, a cultivar DKB 390 apresentou plantas mais altas, com maior inserção da primeira espiga, maior diâmetro do colmo e produtividade quando cultivada no Latossolo Vermelho de textura média irrigado (Quadros 3 e 4).

Quadro 3. Valores de F calculados pela análise de variância para altura das plantas (cm), inserção da primeira espiga (cm), diâmetro do segundo internódio do colmo $(\mathrm{mm})$, massa de matéria seca das plantas e produtividade $\left(\mathrm{t} \mathrm{ha}^{-1}\right)$, índice de colheita e número de espigas por plantas, nos diferentes níveis de compactação e cultivares do Latossolo Vermelho

\begin{tabular}{|c|c|c|c|c|c|c|c|}
\hline $\begin{array}{l}\text { Causa de } \\
\text { variação }\end{array}$ & $\begin{array}{c}\text { Altura da } \\
\text { planta }\end{array}$ & Inserção & Diâmetro & Matéria seca & Produtividade & $\begin{array}{c}\text { Índice de } \\
\text { produtividade }\end{array}$ & $\begin{array}{l}\text { Espigas por } \\
\text { planta }\end{array}$ \\
\hline Compactação (C) & $6,430 * *$ & $2,720 \mathrm{~ns}$ & $5,066^{* *}$ & $3,521^{*}$ & $9,91^{* *}$ & $1,044^{\mathrm{ns}}$ & $0,54^{\mathrm{ns}}$ \\
\hline Cultivar (Cult) & $158,877^{* *}$ & $905,033^{* *}$ & $12,035^{*}$ & $6,836^{\mathrm{ns}}$ & $22,898^{*}$ & $0,026^{\mathrm{ns}}$ & $3,18^{\text {ns }}$ \\
\hline $\mathrm{C} \times \mathrm{Cult}$ & $2,250 \mathrm{~ns}$ & $1,550 \mathrm{~ns}$ & $0,747 \mathrm{~ns}$ & $0,588^{\mathrm{ns}}$ & $1,345^{\mathrm{ns}}$ & $1,117^{\mathrm{ns}}$ & $0,47^{\mathrm{ns}}$ \\
\hline CV1 (\%) & 3,31 & 6,10 & 6,29 & 15,60 & 7,78 & 13,79 & 5,83 \\
\hline CV2 (\%) & 1,72 & 2,27 & 6,67 & 14,94 & 6,15 & 19,25 & 6,34 \\
\hline Média geral & 229,119 & 132,471 & 2,218 & 9,592 & 9,880 & 1,037 & 15,33 \\
\hline
\end{tabular}

CV1 (\%): coeficiente de variação referente ao fator compactação; CV2 (\%): coeficiente de variação referente ao fator cultivar. 
Quadro 4. Valores médios e erros-padrão de altura das plantas, inserção da espiga, diâmetro e produtividade para as cultivares de milho DKB 390 e DAS $2 B 720$

\begin{tabular}{|c|c|c|c|c|}
\hline \multirow{2}{*}{ Cultivar } & \multicolumn{4}{|c|}{ Característica agronômica do milho } \\
\hline & Altura da planta & Inserção $1^{\mathrm{a}}$ espiga & Diâmetro & Produtividade \\
\hline & & 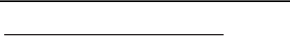 & $\mathrm{mm}$ & $\mathrm{t} \mathrm{ha}^{-1}$ \\
\hline DKB & $236 \pm 1,75 \mathrm{a}$ & $146 \pm 1,36 \mathrm{a}$ & $2,292 \pm 0,04 \mathrm{a}$ & $10,299 \pm 0,29 \mathrm{a}$ \\
\hline DAS & $222 \pm 1,92 \mathrm{~b}$ & $119 \pm 1,68 \mathrm{~b}$ & $2,144 \pm 0,03 \mathrm{~b}$ & $9,460 \pm 0,19 \mathrm{~b}$ \\
\hline
\end{tabular}

Médias seguidas da mesma letra não diferem estatisticamente pelo teste de Tukey a $5 \%$. Letras minúsculas comparam na coluna.

\section{CONCLUSÕES}

1. A macroporosidade e resistência do solo à penetração foram as propriedades físicas do solo mais sensíveis à compactação.

2. O índice $S$ apresentou correlação positiva com a produtividade de milho; entretanto, somente a partir do limite de $\mathrm{S} \leq 0,035$, estabelecido para uma condição de solo desestruturado, ocorreram perdas acentuadas na produtividade de milho.

3. A produtividade dos híbridos de milho foi significativamente menor quando a resistência do solo à penetração atingiu o valor de $2,15 \mathrm{MPa}$, determinada na tensão de $100 \mathrm{hPa}$.

4. Os híbridos simples de milho DKB 390 e DAS 2B710 não diferiram entre si quando submetidos aos diferentes níveis de compactação. Entretanto, o híbrido DKB 390 apresentou maior altura das plantas, inserção da primeira espiga, diâmetro do colmo e produtividade, sendo essas características intrínsecas do próprio material.

\section{AGRADECIMENTOS}

À Fundação de Amparo à Pesquisa do Estado de São Paulo (FAPESP), pela bolsa de estudos concedida ao primeiro autor. Os agradecimentos são extensivos ao Conselho Nacional de Desenvolvimento Científico e Tecnológico (CNPq), pela bolsa de produtividade em pesquisa ao segundo autor, e ao Pólo Alta Mogiana da Agência Paulista de Tecnologia para o Agronegócio (Apta), Colina (SP), pela concessão da área experimental.

\section{LITERATURA CITADA}

ABREU, S.L.; REICHERT, J.M. \& REINERT, D.J. Escarificação mecânica e biológica para redução da compactação em Argissolo franco-arenoso sob plantio direto. R. Bras. Ci. Solo, 28:519-531, 2004.
ALMEIDA, C.X.; CENTURION, J.F.; FREDDI, O.S.; JORGE, R.F. \& BARBOSA, J.C. Funções de pedotransferência para a curva de resistência do solo à penetração. R. Bras. Ci. Solo, 32:2235-2243, 2008.

ARGENTON, J.; ALBUQUERQUE, J.A. \& BAYER, C. Comportamento de atributos relacionados com a forma da estrutura de Latossolo Vermelho sob sistemas de preparo e plantas de cobertura. R. Bras. Ci. Solo, 29:425$435,2005$.

BEUTLER, A.N.; CENTURION, J.F.; CENTURION, M.A.P.C.; \& SILVA, A.P. Efeito da compactação na produtividade de cultivares de soja em Latossolo Vermelho. R. Bras. Ci. Solo, 30:787-794, 2006.

BEUTLER, A.N.; CENTURION, J.F.; CENTURION, M.A.P.C.; LEONEL, C.L.; JOÃO, A.C.G. S. \& FREDDI, O.S. Intervalo hídrico ótimo no monitoramento da compactação e da qualidade física de um Latossolo Vermelho cultivado com soja. R. Bras. Ci. Solo, 31:12231232, 2007.

BLAKE, G.R. \& HARTGE, K.H. Bulk density. In: KLUTE, A., ed. Methods of soil analysis: Part 1 - Physical and mineralogical methods. Madison, American Society of Agronomy, 1986. p.363-375.

BORGES, E.N.; NOVAIS, R.F.; FERNANDEZ, B. \& BARROS, N.F. Respostas de variedades de soja à compactação de camadas de solo. R. Ceres, 35:553-568, 1988.

BUSHAMUKA, V.N. \& ZOBEL, R.W. Differential genotypic and root type penetration of compacted soil layers. Crop Sci., 38:776-781, 1998.

DANiELSON, R.E. \& SUTHERLAND, P.L. Porosity. In: KLUTE, A., ed. Methods of soil analysis: Part 1 - Physical and mineralogical methods. Madison, American Society of Agronomy, 1986. p.443-460.

DEXTER A.R. Soil physical quality: Part II. Friability, tillage, tilth and hard-setting. Geoderma, 120:215-225, 2004b.

DEXTER A.R. Soil physical quality: Part III. Unsaturated hydraulic conductivity and general conclusions about $\mathrm{S}$ theory. Geoderma, 120:227-239, 2004c.

DEXTER, A.R. Soil physical quality: Part I. Theory. Effects of soil texture, density, and organic matter, and effects on root growth. Geoderma, 120:201-214, 2004a. 
FOLONI, J.S.S.; CALONEGO, J.C. \& LIMA, S.L. Efeito da compactação do solo no desenvolvimento aéreo e radicular de cultivares de milho. Pesq. Agropec. Bras., 38:947-953, 2003.

FREDDI, O.S. Avaliação do intervalo hídrico ótimo em Latossolo Vermelho cultivado com milho. Jaboticabal, Faculdade de Ciências Agrárias e Veterinárias, 2007. 105p. (Tese de Doutorado)

GARDNER, W.H. Water content. In: KLUTE, A., ed. Methods of soil analysis: Part 1 - Physical and mineralogical methods. Madison, American Society of Agronomy, 1986. p.493-541.

GEE, G.W. \& BAUDER, J.W. Particle-size analysis. In: KLUTE, A., ed. Methods of soil analysis: Part 1 - Physical and mineralogical methods. Madison, American Society of Agronomy, 1986. p.383-409.

GOMES, F.P. A estatística moderna na pesquisa agropecuária. Piracicaba, POTAFÓS, 1984. 160p.

GRAVETTER, F.J. \& WALLNAU, L.B. Statistics for the behavioral sciences. St. Paul. West Publishing, 1995. 429p.

KASPERBAUER, M.J. \& BUSSCHER, W.J. Genotypic differences in cotton root penetration of a compacted subsoil layer. Crop Sci., 31:1376-1378, 1991.

KLUTE, A. Water retention: Laboratory methods. In: KLUTE, A., ed. Methods of soil analysis: Part 1 - Physical and mineralogical methods. Madison, American Society of Agronomy, 1986. p.635-660.

QUEIROZ-VOLTAN, R.B.; NOGUEIRA, S.S.S. \& MIRANDA, M.A.C. Aspectos da estrutura da raiz e do desenvolvimento de plantas de soja em solos compactados. Pesq. Agropec. Bras., 35:929-938, 2000.

RAIJ, B.van; CANTARELLA, H.; QUAGGIO, J.A. \& FURLANI, A.M.C. Recomendações de adubação e calagem para o estado de São Paulo. Campinas, Instituto Agronômico/ Fundação IAC, 1997. 285p.

RAIJ, B.van; QUAGGIO, J.A.; CANTARELLA, H.; FERREIRA, M.; LOPES, A.S. \& BATAGLIA, O.C. Análise química do solo para fins de fertilidade. Campinas, Fundação Cargill, 1987. $170 \mathrm{p}$
SECCO, D.; REINERT, D.J.; REICHERT, J.M. \& DA ROS, C.O. Produtividade de soja e propriedades físicas de um Latossolo submetido a sistemas de manejo e compactação. R. Bras. Ci. Solo, 28:797-804, 2004.

SILVA, A.P.; KAY, B.D. \& PERFECT, E. Characterization of the least limiting water range. Soil Sci. Soc. Am. J., 58:1775-1781, 1994.

SILVA, G.J.; MAIA, J.C.S. \& BIANCHINI, A. Crescimento da parte aérea de plantas cultivadas em vaso, submetidas a irrigação subsuperficial e a diferentes graus de compactação de um Latossolo Vermelho-Escuro distrófico. R. Bras. Ci. Solo, 30:31-40, 2006.

SILVA, O.S.; FREDDI, O.S.; CENTURION, J.F.; ARATANI, R.G.; ANDRIOLI, F.F. \& ANDRIOLI, I. Propriedades físicas de um Latossolo Vermelho cultivado no sistema plantio direto. Irriga, 13:191-204, 2008.

SILVA, R.H. \& ROSOLEM, C.A. Crescimento radicular de espécies utilizadas como cobertura decorrente da compactação do solo. R. Bras. Ci. Solo, 25:253-260, 2001.

SOYELU, L.O.; AJAYI, S.A.; ALUKO, O.B. \& FAKOREDE, M.A.B. Varietal differences in development of Maize (Zea mays L.) seedlings on compacted soil. Crop Sci., 186:157166, 2001.

STRECK, C.A.; REINERT, D.J.; REICHERT, J.M \& KAISER, D.R. Modificações em propriedades físicas com a compactação do solo causada pelo tráfego induzido de um trator em plantio direto. Ci. Rural, 34:755-760, 2004.

THOMASSON, A.J. Towards an objective classification of soil structure. J. Soil Sci., 29:38-46, 1978.

TORMENA, C.A.; SILVA, A.P. \& LIBARDI, P.L. Caracterização do intervalo hídrico ótimo de um Latossolo Roxo sob plantio direto. R. Bras. Ci. Solo, 22:573-581, 1998.

TORMENA, C.A.; SILVA, A.P.; IMHOFF, S.C. \& DEXTER, A.R. Quantification of the soil physical quality of a tropical Oxisol using the S index. Sci. Agric., 65:56-60, 2008.

van GENUCHTEN, M.T.A. A closed-form equation for predicting the hydraulic conductivity of unsaturated soils. Soil Sci. Soc. Am. J., 44:892-897, 1980.

YU, L.; RAY, J.D.; O‘TOOLE, J.C. \& NGUYEN, H.T. Use of wax-petrolatum layers for screening rice root penetration. Crop Sci., 35:684-687, 1995. 
